\title{
ARTIFACTS IN THE ANALYSIS AND ASSESSMENT OF LOW-COST CONTAINERS FOR SAMPLING AND STORING GREENHOUSE GASES
}

\author{
Rafael C. Abruzzi ${ }^{\mathrm{b}}$, Beatriz Bonetti ${ }^{\mathrm{b}}$, Marçal J.R. Pires ${ }^{\mathrm{a}, \mathrm{b}, *,(\mathbb{D}}$, Berenice. A. Dedavid ${ }^{\mathrm{b}}$ and Arthur K. Bitencourt $^{\mathrm{b}}$ \\ ${ }^{a}$ Escola de Ciências, Pontifícia Universidade Católica do Rio Grande do Sul, 90619-900 Porto Alegre - RS, Brasil

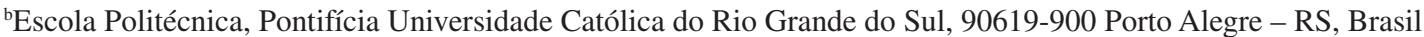

Recebido em 13/07/2018; aceito em 01/10/2018; publicado na web em 22/10/2018

\begin{abstract}
The objectives of this study were twofold: to assess two chromatographic methods for the analysis of greenhouse gases (GHG) and carbon monoxide, and to propose and evaluate a low-cost and reusable alternative system for their sampling and storage, using 10 different container configurations (flasks and bags). To that end, standard samples containing the gases of interest $\left(\mathrm{CO}_{2}, \mathrm{CH}_{4}\right.$ and $\mathrm{CO}$ ) and different types of real samples were tested. Finally, procedures for the sampling, storage and analysis of $\mathrm{CO}_{2}$ and $\mathrm{CH}_{4}$ were evaluated and optimized. Two chromatographic methods were applied, using different analysis conditions and columns. Gas chromatography analysis of sample stability and container reusability demonstrated that borosilicate flasks with butyl rubber and PTFE/silicone septa are ideal for storing samples, allowing up to 5 successive sampling cycles with no significant loss of recovery. For larger volume samples, multilayer foil bags are the most stable for the compounds analyzed. The tests conducted with real and synthetic gas samples under optimized chromatography conditions using both methods indicated satisfactory performance for $\mathrm{CO}_{2}$ and $\mathrm{CH}_{4}$ quantification. However, $\mathrm{CO}$ analysis in the column with a polystyrene-divinylbenzene stationary phase (Method 1) produced an artifact due to the presence of oxygen in the samples, restricting its quantification.
\end{abstract}

Keywords: greenhouse gases; analysis artifact; containers; gas sampling.

\section{INTRODUCTION}

Global atmospheric concentrations of primary greenhouse gases (GHG) such as carbon dioxide $\left(\mathrm{CO}_{2}\right)$ and methane $\left(\mathrm{CH}_{4}\right)$, produced by natural sources and by human activities involving fossil fuels and changes in land use, have increased significantly, with a sharp rise in the last decade. ${ }^{1} \mathrm{CO}_{2}$ accounts for $77 \%$ of total $\mathrm{GHG}$ emissions (32 $\mathrm{Gt} \mathrm{CO}_{2}$ in 2014), with the transport sector responsible for $23 \%$ of total fossil fuel-related emissions. ${ }^{2}$ Methane, 23 times more potent than $\mathrm{CO}_{2},{ }^{1}$ is emitted during the production and transport of coal and is one of the main sources of GHG emissions, representing $9 \%$ of the total on $\mathrm{CO}_{2}$ equivalent basis. ${ }^{3}$ Carbon monoxide (CO) is also present in many emissions and even low levels (>9 ppm, CONAMA $)^{4}$ can pose environmental and occupational hazards (39 ppm, NR15 and $50 \mathrm{ppm}, \mathrm{MSHA})^{6}$. Given that $\mathrm{CO}$ is considered a contaminant that may interfere in the separation/control of $\mathrm{GHG},{ }^{7}$ concomitant monitoring with GHG is important.

Gas chromatography (GC) is the most widely used method to monitor GHG in ambient air. ${ }^{8}$ Among the different types of detectors used, the flame ionization detector (FID) stands out for its simplicity, low cost, easy use, response speed, high sensitivity, linearity and reliability. ${ }^{9}$ When combined with a methanator, FID allows direct quantification of methane, besides $\mathrm{CO}$ and $\mathrm{CO}_{2}$ after catalytic reduction to methane with excess hydrogen, in broad concentration ranges and high sensitivity. ${ }^{9,10}$ The complete chromatographic separation of the gases of interest $\left(\mathrm{CO}, \mathrm{CO}_{2}, \mathrm{CH}_{4}\right)$ from permanent gases such as $\mathrm{O}_{2}$ is often not evaluated, since oxygen is not expected to interfere with the FID detecttion. Among the few studies that report an artifact in this analysis, the most prominent is the article by Kaminski et al. ${ }^{11}$ on the determination of $\mathrm{CO}, \mathrm{CH}_{4}$ and $\mathrm{CO}_{2}$ in refinery gas using a GC-FID coupled with a methanator. The authors found that $\mathrm{CO}$ concentration can be overestimated due to $\mathrm{CO}$ co-elution with $\mathrm{O}_{2}$ and its undesired production in the methanator. If the catalyzer

*e-mail: mpires@pucrs.br becomes partially carbonized as a result of the high hydrocarbon and $\mathrm{CO}_{2}$ levels passing through it, carbon can react with $\mathrm{O}_{2}$ or $\mathrm{CO}_{2}$ to form $\mathrm{CO}$. This artifact can cause significant errors in $\mathrm{CO}$ determination when using this technique, making it essential to carefully assess the column and method used for quantification. The interferences described above are particularly important and must be taken into account when analyzing traces of $\mathrm{CO}$. This is the case of ambient air in coal mines, where high $\mathrm{CH}_{4}$ levels occur in association with low concentrations of $\mathrm{CO}_{2}$ and $\mathrm{CO}$, among other gases. ${ }^{12,13}$

In addition to carefully determining chromatographic parameters, it is important to ensure the integrity of gaseous samples between collection and analysis. Despite the development of miniature portable gas chromatographs ${ }^{13}$ that enable in situ monitoring, most laboratories still use benchtop equipment. As such, it is essential to assess the performance of sampling systems during transport and storage of the samples. ${ }^{14}$ Notwithstanding the importance of these tests, few studies evaluate the analytical quality of the sampling systems used. ${ }^{14,15}$ The two most widely used systems for GHG collection are flasks and sampling bags. Borosilicate flasks or those made from polymeric material have punctured septa that enable the evacuation, collection and transfer of samples to the GC. They are easy to use, inexpensive and reusable, and the septa are replaced after a certain number of punctures. The quality of the vacuum and its maintenance until collection, the permeability of septa to analytes and any contaminants in the air as well as their reactivity with the surfaces of the flask are potential weaknesses that must be assessed when using this type of container. Sampling bags are made from a number of different materials, including polyvinyl fluoride, polytetrafluoroethylene, aluminum polyester, polyvinylidene chloride and fluorocarbons. ${ }^{16,17}$ They are available in different volumes, which may be useful in analyses that require a larger number of replicates. However, sample collection using these containers requires a sampling pump, making the process more complex and expensive. These containers also have septa through which the sample is transferred to the analysis system. The permeability and reactivity of the analytes to the largest free 
surface of the sampler is more critical in sampling bags than flasks. The difficulties of reuse and the relatively short storage time (24-48 h) should also be considered. ${ }^{18}$

This study has two primary objectives: i) to assess the impact of the artifact caused by $\mathrm{O}_{2}$ in the methanator coupled to FID detection of $\mathrm{CO}$, and ii) to propose and evaluate a low-cost and reusable alternative system for $\mathrm{CO}_{2}, \mathrm{CH}_{4}$ and $\mathrm{CO}$ sampling and storage, using 10 different container configurations. To that end, we tested standard samples containing the gases of interest and potential contaminants, as well as different types of real samples. Finally, validated and optimized procedures for the sampling, storage and analysis of $\mathrm{CO}_{2}$ and $\mathrm{CH}_{4}$ were proposed and tested using different types of real samples.

\section{MATERIAL AND METHODS}

\section{Preparing containers for GHG sampling and storage}

Commercial and alternative (homemade) containers were tested in order to ensure the integrity of samples collected in different environments, in addition to assessing the possible reuse of the materials to reduce operating costs. In storage tests of gas samples, the three different flask types described below (Table 1) were tested.

Alternative flasks (AF) are reused materials from DQO analysis kits (Borosilicate glass with plastic screw cap, Bereich Aqualytic, Germany) that are normally used once and then discarded as laboratory waste (volume of $12 \mathrm{~mL}$ ). The flasks were previously washed with deionized water and detergent $\left(\right.$ Extran $\left.^{\circledR}\right)$ and dried in an oven $\left(3 \mathrm{~h}\right.$ at $\left.100{ }^{\circ} \mathrm{C}\right)$ to prevent sample contamination. The plastic caps were punctured to allow the entry of needles through the septa, installed between the cap and the body of the borosilicate flask. Three septa configurations were tested: Silicone (AF-S, Termogreen ${ }^{\circledR}$ LB-2), PTFE/Silicone (AF-TS) and PTFE/Silicone + Butyl Rubber/PTFE (AF-BR). The septa were selected as a function of their availability, cost and compatibility with the analytes of interest, and used on chromatograph equipment (AF-S and AF-TS) as well as commercial containers (AF-S, AF-TS, and AF-BR). It is important to underscore that the double septa (PTFE/Silicone + Butyl Rubber/PTFE), were employed either as protective caps or an impermeable barrier to the gases of interest, similar to those used on Exetainer ${ }^{\circledR}$ commercial containers (LABCO, UK). Two commercial flasks (VC and EX) were used for comparison: one low cost (Table 1) polymer-based flask with a $4 \mathrm{~mL}$ capacity and rubber septum (VC-R, Vacutainer ${ }^{\circledR}$ ), used to collect blood samples, and a $12 \mathrm{~mL}$ borosilicate flask (EX-BR, Exetainer $\left.{ }^{\circledR}\right)$ with a combination of two septa (PTFE/Silicone and Butyl Rubber), used to collect gases. Vacutainer ${ }^{\circledR}$ flasks can be purchased or acquired from institutions that discard them after expiration. These flasks were submitted to the same cleaning procedure as the borosilicate containers. All the flasks were subsequently purged with nitrogen $\left(\mathrm{N}_{2}, 99.9992 \%\right.$ purity) and evacuated for 15 min using a pumping system $\left(1 \times 10^{-4}\right.$ mbar, T-Station75, Edwards) no more than $24 \mathrm{~h}$ before collections. For the vacuum level tests, in line with Rochette and Bertrand, ${ }^{19}$ 10 flasks (AF-BR) with double septa were randomly selected and individually weighed. Next, the flasks were evacuated and divided into pairs in order to monitor the vacuum level for up to ten days. Each day two flasks were punctured with needles connected to a water bath, whereby the difference in pressure caused them to fill with water. The flasks were weighed after filling to determine the amount introduced as a result of the pressure difference, thus indicating the effectiveness of the vacuum. These tests also made it possible to determine the number of times flasks could be reused without affecting collection efficiency.
Similar tests were carried out with sampling bags, which have a larger volume capacity. The characteristics of each bag are shown in Table 1. Two of the bags were made from PVDF with a silicone septum (Thermogreen ${ }^{\circledR}$ LB-2) and capacities of $1.0 \mathrm{~L}(\mathrm{BC})$ and $0.6 \mathrm{~L}(\mathrm{BE})$.

Two others (denominated BA and BB) had the same type of collection valve (screw cap valve - SCV), but different volumes (1.0 and 3.0 L), and their main component was not indicated by the manufacturer The fifth (BD) was a multilayer PE/Al sampling bag with a Thermogreen ${ }^{\circledR}$ LB-2 septum. Before use, all the bags were purged several times with nitrogen, the same balance gas as that used for the standard gas mixtures.

\section{Gas sampling procedures}

After purging and evacuation, the containers were submitted to collection and storage tests (Figure 1S). These tests used different types of synthetic and real samples containing the gases of interest: a) synthetic samples obtained by standard gas mixture $\mathrm{A} 1\left(\mathrm{CO}_{2}\right.$ $10,000 \mathrm{ppm}, \mathrm{CO} 5,000 \mathrm{ppm}$ and $\mathrm{CH}_{4} 50,000 \mathrm{ppm}$ ); b) soil emission samples (collected using chamber method in the garden of the School of Sciences - PUCRS); c) gas samples collected in the Conceição Tunnel (heavy vehicular traffic, Porto Alegre, Brazil); d) ambient air from underground coal mines (Criciúma, Brazil); e) exhaust fumes from a car (Ford Fiesta 2008, 1.0 L engine) filled with gasoline (blended with $27 \%$ ethanol anhydrous).

Two forms of standard gas mixture A1 were used in the tests, namely as a concentrated gas, and diluted ten times with nitrogen $\left(\mathrm{N}_{2} ; 99.9992 \%\right)$ using a dilution system built in the laboratory (Figure 1Sa). The concentration of diluted gas sample were checked by GC analysis, presenting an uncertainty $<1 \%$ compared to the nominal concentration.

The sampling bags were filled gas samples with above atmospheric pressure up to the volume indicated by the supplier, directly from the gas line. Aliquots of $15 \mathrm{~mL}$ were transferred to the pre-evacuated $12 \mathrm{~mL}$ flasks and $4 \mathrm{~mL}$ aliquots to the $5 \mathrm{~mL}$ flasks, with a syringe with hypodermic needle, to create slightly higher pressure than atmospheric pressure inside the flask. The soil emission samples (Figure 1Sb) were collected in May 2015, $1 \mathrm{~h}$ after sampling chamber installation to allow sufficient stabilization of the system. Samples from the Conceição Tunnel were collected in August 2016 and those from the underground coal mine in October 2015. For sampling bags this procedure involves drawing the ambient air into the container through the vacuum obtained using a vacuum sampling system (Supelco, Figure $1 \mathrm{Sd}$ ) preventing contamination of the sample, while the flasks were filled using a syringe (Figure $1 \mathrm{Sc}$ ).

\section{Stability tests during storage}

The samples collected in different environments (underground coal mine, Conceição Tunnel and soil emission) and the synthetic sample were assessed to determine their stability in the containers, with storage time varying from 0 to $240 \mathrm{~h}$. Sampling was conducted in triplicate at all the collection sites. In the soil vapor tests, the initial values attributed were those of the aliquots sampled directly from the system before collection in the flasks. For the Conceição Tunnel and coal mine samples, initial recovery was considered to be $100 \%$, since the first analyses were performed 2 and $24 \mathrm{~h}$ after sampling, respectively. The results of these tests were expressed as recovery percentages $(\mathrm{R} \%)$, calculated by dividing the average gas concentration $(n=3)$ in time $t$ by the average concentration $(n=3)$ at the starting time $\left(\mathrm{t}_{0}\right)$ multiplied by 100 . 
Table 1. Description and identification of the different sampling containers used

\begin{tabular}{|c|c|c|c|c|c|c|}
\hline $\begin{array}{l}\text { Type } \\
\text { Code }\end{array}$ & Commercial name & $\begin{array}{l}\text { Cap. } \\
\text { (L) }\end{array}$ & Container Composition & Fitting/Other characteristics & $\begin{array}{l}\text { Cost } \\
\text { US\$ }\end{array}$ & Supplier \\
\hline \multicolumn{7}{|l|}{ Flasks } \\
\hline VC-R & Vacutainer ${ }^{\circledR}$ Rubber & 0.004 & Polyvinyl Chloride & Rubber septum & 0.28 & Biocon \\
\hline EX-BR & $\begin{array}{c}\text { Exetainer }^{\circledR} \text { Butyl } \\
\text { Rubber }\end{array}$ & 0.012 & Borosilicate glass & PTFE/Silicone and Butyl Rubber & 1.57 & LABCO, UK \\
\hline AF-S & $\begin{array}{l}\text { Alternative Flask- } \\
\text { Teflon/Silicone }\end{array}$ & 0.012 & Borosilicate glass & $\begin{array}{c}\text { Thermogree }{ }^{\circledR} \text { LB-2, } \varnothing 12.5 \mathrm{~mm}, \\
\text { Silicone }\end{array}$ & 2.03 & $\begin{array}{l}\text { Bereich Aqualytic / } \\
\text { Supelco }\end{array}$ \\
\hline AF-TS & $\begin{array}{c}\text { Alternative } \\
\text { Flask- Silicone }\end{array}$ & 0.012 & Borosilicate glass & White $\varnothing 11 \mathrm{~mm}$, PTFE/Silicone & 0.40 & $\begin{array}{c}\text { Bereich Aqualytic / } \\
\text { Supelco } \\
\end{array}$ \\
\hline AF-BR & $\begin{array}{l}\text { Alternative Flask- } \\
\text { Butyl Rubber }\end{array}$ & 0.012 & Borosilicate glass & $\begin{array}{l}\text { Blue } \varnothing 13 \mathrm{~mm} \text {, PTFE/Silicone and } \\
\text { Red } \varnothing 13 \mathrm{~mm} \text {, Butyl rubber/PTFE }\end{array}$ & 1.22 & $\begin{array}{l}\text { Bereich Aqualytic / } \\
\text { Supelco }\end{array}$ \\
\hline \multicolumn{7}{|l|}{ Bags } \\
\hline BA & $\begin{array}{l}\text { SamplePro }^{\circledast} \\
\text { FlexFilm }\end{array}$ & 1.0 & information not provided & Screw Cap Valve & 13.7 & SKC Inc. \\
\hline $\mathrm{BB}$ & $\begin{array}{c}\text { Tedlar }^{\circledR} \text { Air } \\
\text { Sample Bags }\end{array}$ & 3.0 & information not provided & Screw Cap Valve & 18.3 & SKC Inc. \\
\hline \multirow[t]{2}{*}{$\mathrm{BC}$} & Tedlar $^{\circledast}$ Gas & 1.0 & $\begin{array}{l}\text { PVDF Polyvinylidene } \\
\text { Fluoride }\end{array}$ & $\begin{array}{c}\text { Push/Pull lock valve, } \\
\text { Thermogreen }{ }^{\circledR} \text { LB-2 septum }\end{array}$ & 12.5 & Supelco \\
\hline & Sampling Bag & & & & & \\
\hline \multirow[t]{2}{*}{$\mathrm{BD}$} & $\begin{array}{l}\text { Supel }{ }^{\mathrm{TM}} \text {, Inert } \\
\text { Multi-Layer Foil }\end{array}$ & 1.0 & $\mathrm{PE} / \mathrm{Al}$ & $\begin{array}{l}\text { Screw Cap Valve, Thermogreen } \\
\text { LB-2 Septum } \\
\end{array}$ & 11.4 & Supelco \\
\hline & & & Polyethylene; Aluminum & & & \\
\hline $\mathrm{BE}$ & $\begin{array}{l}\text { Tedlar }^{\circledast} \text { Gas } \\
\text { Sampling Bag }\end{array}$ & 0.6 & $\begin{array}{l}\text { PVDF Polyvinylidene } \\
\text { Fluoride }\end{array}$ & $\begin{array}{c}\text { Push/Pull lock valve, } \\
\text { Thermogreen }{ }^{\circledast} \text { LB-2 septum }\end{array}$ & 11.8 & Supelco \\
\hline $\begin{array}{l}\text { Vacuum Sampling } \\
\text { Pump }\end{array}$ & & & $\begin{array}{c}\text { Dimensions } \\
(15.2 \times 20.3 \times 23.6 \mathrm{~cm}) \\
\text { Weight: } 2.3 \mathrm{~kg}\end{array}$ & & 1.070 .00 & Supelco \\
\hline
\end{tabular}

\section{Gas chromatography analysis}

The gas samples were identified and quantified using a PerkinElmer Clarus 580 gas chromatograph coupled with an FID (flame ionization detector) and a methanator positioned between the column and detector, containing Ni (Catalyst 9000 Methanizer, PerkinElmer). Helium was used as carrier gas (He; 99.9997\%). Hydrogen $\left(\mathrm{H}_{2} ; 99.9992 \%, 45 \mathrm{~mL} \mathrm{~min}^{-1}\right)$ was used in the methanator to reduce $\mathrm{CO}$ and $\mathrm{CO}_{2}$ to $\mathrm{CH}_{4}$. Some analyses were performed using a Shimadzu GC-2014 gas chromatograph coupled with an FID. ${ }^{20}$

Two columns (described in Table 1S) were tested for sample analysis, in order to determine the interference of the stationary phase and assess performance in identifying and quantifying the standard gas mixture and real GHG samples. The column used in method 1 was a 30-meter-long mega-bore Elite-Q Plot with an internal diameter of $0.53 \mathrm{~mm}$ and $20-\mu \mathrm{m}$-thick polystyrene-divinylbenzene stationary phase film. The oven temperature was set at $50{ }^{\circ} \mathrm{C}$ (isothermal method). Injector and detector temperatures were 200 and $350{ }^{\circ} \mathrm{C}$, respectively, with a carrier gas (He) flow rate of $10 \mathrm{~mL} \mathrm{~min}^{-1}$. Total analysis time after optimization was $5 \mathrm{~min}$. A 30-meter-long megabore Carboxen 1010 column was used in method 2, with a $0.53 \mathrm{~mm}$ internal diameter and carbon molecular sieve phase. The temperature ramp of the oven was $35^{\circ} \mathrm{C}(6 \mathrm{~min})$, at a rate of $20{ }^{\circ} \mathrm{C} \mathrm{min}-1$ up to $150^{\circ} \mathrm{C}(2 \mathrm{~min})$. The injector and detector temperatures were 200 and $400{ }^{\circ} \mathrm{C}$, respectively, and helium was used as carrier gas (flow rate of $10 \mathrm{~mL} \mathrm{~min}-1$ ). Total analysis time after optimization was $20 \mathrm{~min}$. The samples were injected using a gastight microsyringe $(500 \mu \mathrm{L})$.

Five gas reference standards were used (Table $2 \mathrm{~S}$ ) to calibrate the equipment and study the artifact of chromatography analysis. The calibration curves were constructed by diluting these gases using two $100 \mathrm{~mL}$ capsules of gas each. The capsules were fitted with silicone septa and their volumes calibrated. One was filled with standard $\mathrm{N}_{2}$ (A5), used for dilution, and the other with standard gas mixture A1 (CO 5,000 ppm, $\mathrm{CO}_{2}$ 10,000 ppm and $\mathrm{CH}_{4}$ 50,000 ppm) for high concentration curves or $\mathrm{A} 2$ (CO $503 \mathrm{ppm}$ and $\mathrm{CH}_{4} 504 \mathrm{ppm}$ ) for low concentration curves. A $10 \mathrm{~mL}$ gastight syringe was used to transfer gas from one capsule to another. Tests were conducted with standard gas mixture samples in order to assess methods 1 and 2 (Table 1S). Initial testing was performed using a mega-bore Elit-Q Plot column (method 1), recommended by the manufacturer for analyzing low concentrations of gases such as $\mathrm{CO}, \mathrm{CH}_{4}$ and $\mathrm{CO}_{2}$. The gas flow rate (split) was 1:10 and the syringe used to inject samples into the gas chromatograph was modified. Since the needle was removable, the syringe was fitted with a valve to prevent contamination by outside air (Figure 1Se). In both methods, a volume of $300 \mu \mathrm{L}$ was injected for each sample, with the exception of the calibration curves, which used different volumes for analysis (50 to $300 \mu \mathrm{L}$ ).

\section{Tests to determine the presence of an artifact in GC-FID analysis with a methanator}

Concentrated and diluted (100x) samples of standard gas mixture A1, which contains the three gases of interest, were injected to determine the presence of an artifact in analyses. Next, samples of standard gas A3 (synthetic air; 21\% $\mathrm{O}_{2}$ and 79\% $\mathrm{N}_{2}$ ) and different volumes of $\mathrm{A} 4\left(\mathrm{O}_{2}\right)$ were injected to assess the presence of oxygen in $\mathrm{CO}$ determination. Tests were also carried out with A5 $\left(\mathrm{N}_{2}\right)$ since it was used as balance gas and did not contain $\mathrm{CO}_{2}$, making it possible 
to evaluate possible sample contamination by $\mathrm{CO}_{2}$ from the ambient air during injection. These tests were conducted for the two methods in both the Carbonex 1010 (method 2) and Elit-Q Plot (method 1), recommended for the analysis of these gases in ambient air. To assess the behavior of real samples with higher and varied $\mathrm{CO}$ and $\mathrm{CO}_{2}$ concentrations, tests were conducted using car exhaust fumes in both methods. The car in question runs on gasoline containing anhydrous ethanol $(27 \%)$. Samples were taken at different times according to acceleration intensity, using flasks $(15 \mathrm{~mL})$ filled with the aid of a syringe.

\section{RESULTS AND DISCUSSION}

\section{Validation of the analysis methods}

Analysis of standard gas mixture A1 in the Elite-Q Plot column (method 1) exhibited good separation and symmetrical peaks (Figure 1a). The figure shows three peaks with retention times were $1.706 \mathrm{~min}, 1.793 \mathrm{~min}$ and $2.092 \mathrm{~min}$ for $\mathrm{CO}, \mathrm{CH}_{4}$ and $\mathrm{CO}_{2}$, respectively, and the peaks are proportional to the known concentrations of these compounds. Analysis of ambient air samples from the city of Porto Alegre (Brazil) using the same method showed significantly higher $\mathrm{CO}$ levels $(\sim 40 \mathrm{ppm})$ than the average reported by monitoring stations for urban areas $(0.4 \mathrm{ppm}){ }^{4}$
As previously indicated, this artifact was reported by Kaminski et $a l .{ }^{11}$ As such, samples of A3 (synthetic air) were injected to evaluate the behavior of this potential artifact. The results (Figure 1b) indicate unexpected ghost peaks in analyses of these gases using an FID detector. This behavior may affect accurate determination of the gases of interest, such as $\mathrm{CO}$, whose retention time is similar to that of ghost peak with retention time of $1.699 \mathrm{~min}$.

A second ghost peak (retention time $2.097 \mathrm{~min}$ ) was also identified, with the same retention time as $\mathrm{CO}_{2}$. These peaks were unexpected since the FID is only sensitive to the presence of combustible gases. Additional analyses were performed to better understand the behavior of these two peaks. Samples of A5 $\left(\mathrm{N}_{2}\right)$ and $\mathrm{A} 4\left(\mathrm{O}_{2}\right)$ were injected, varying the volumes. It is important to underscore that, depending on how the syringe is used, contamination by ambient air can occur when the samples are transferred from the flasks to the gas chromatograph. As such, the syringe used was fitted with a valve (Figure $1 \mathrm{Se}$ ), which makes it possible to effectively control contamination and determine whether the peaks are the result of this process or can be attributed to other factors. When the adapted syringe was used, the values of second peak (attributed to $\mathrm{CO}_{2}$, Figure 2a) decreased significantly in analyses with A5, meaning the variation may be associated with this mechanism.

It is important to emphasize that $\mathrm{CO}_{2}$ levels in the ambient air may vary according to laboratory activities, since the gas is used in
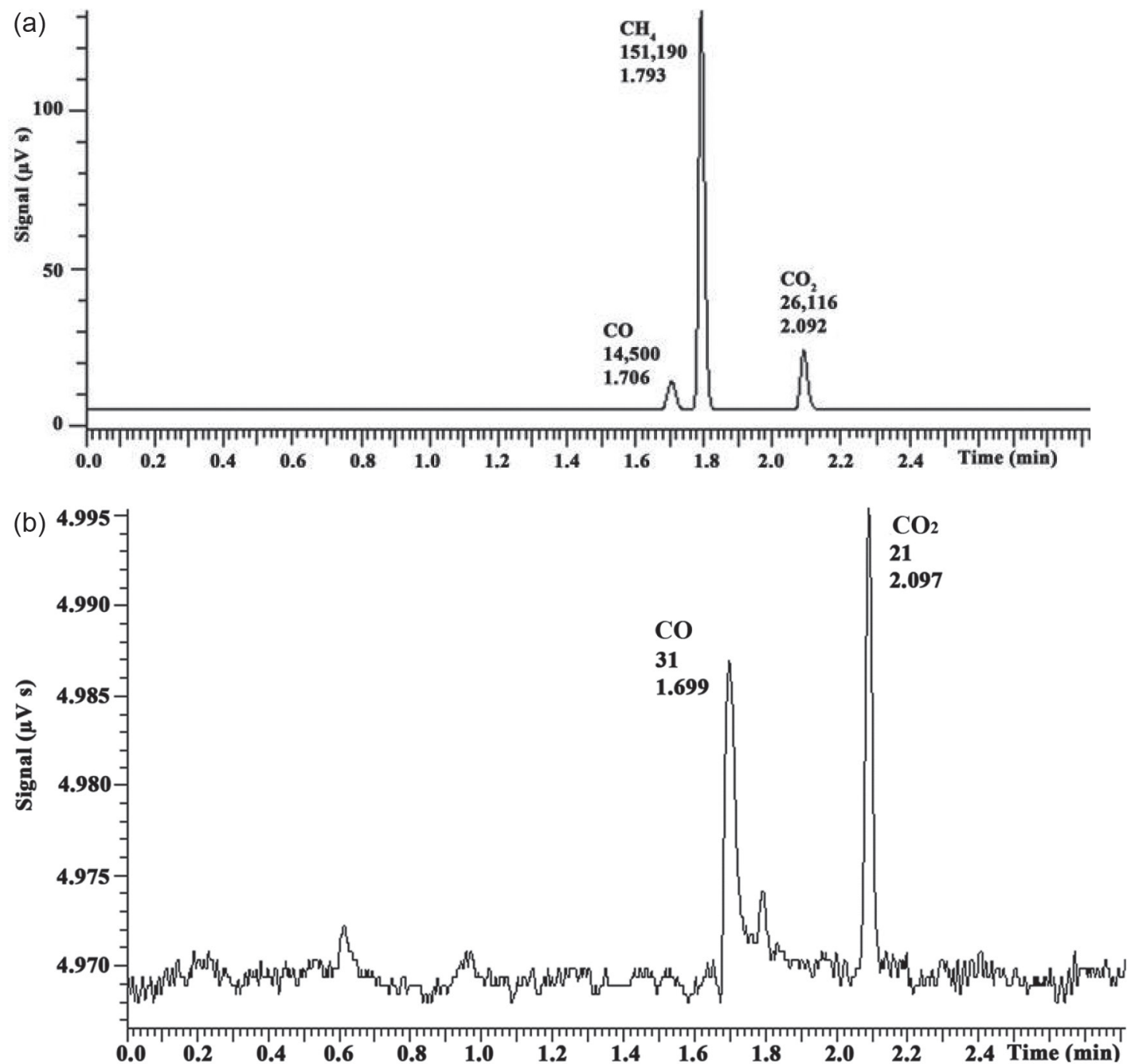

Figure 1. Chromatograms of standard gas mixtures analyzed by Method 1 for: (a) standard A1, and (b) standard A3. Peak areas ( $\mu$ V.s) and retention times (min) are shown within the figure for each peak 

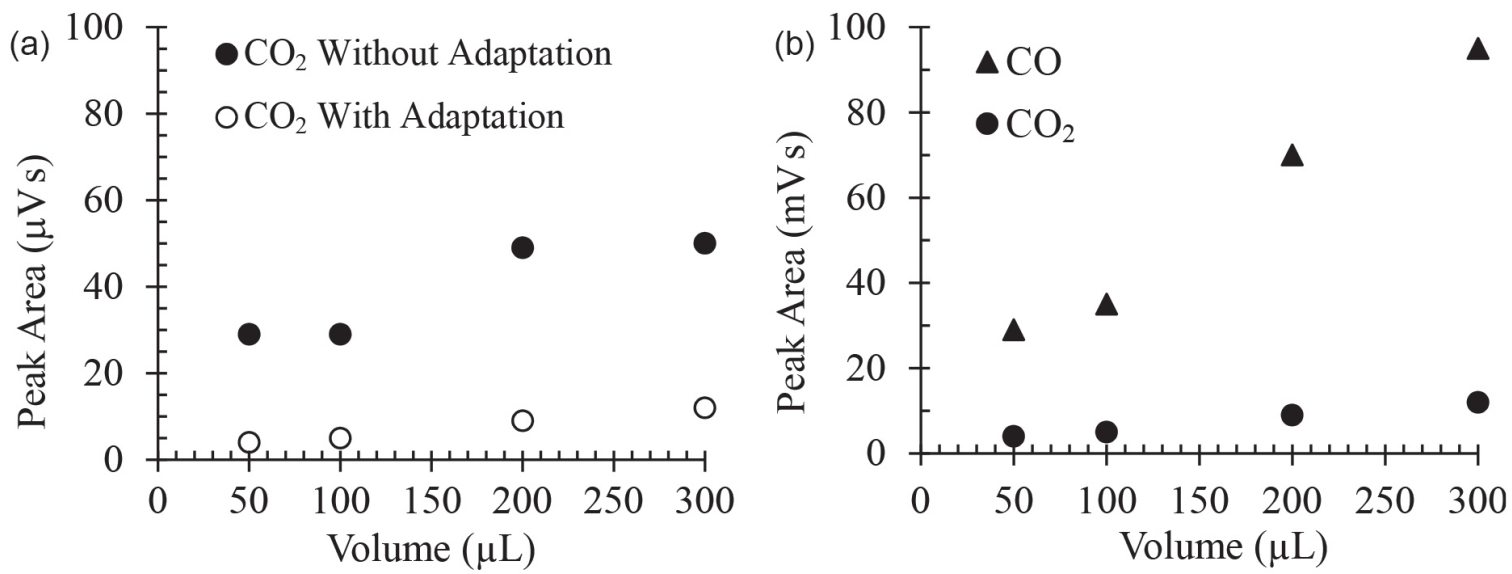

Figure 2. Signals for different amounts of $\mathrm{CO}$ and $\mathrm{CO}_{2}$ analyzed by method 1 for: (a) $\mathrm{CO}_{2}$ analyzed using standard A5, without and with valve adaptation of the syringe, and (b) $\mathrm{CO}$ and $\mathrm{CO}_{2}$ analyzed using the $\mathrm{A} 4$ standard

other studies. The presence of this peak in analyses using injected samples of high purity gases $\left(\mathrm{He}\right.$ and $\mathrm{N}_{2}$ ) that do not produce FID signals is also significant, corroborating its possible association with this type of contamination.

Analyses with A4 $\left(\mathrm{O}_{2}\right)$ produced a considerable increase in peak 1 according to the volume injected, particularly when compared to the results of tests related to second ghost peak (Figure 2b). In light of this behavior, this artifact may be related to the injection mechanism, as discussed by Van Rensburg; Botha and Rohwer, ${ }^{21}$ or analytical problems associated with the methanator and/or FID. According to Kaminski et al. ${ }^{11} \mathrm{CO}$ co-elution with peak 1 is generally more significant in ambient air samples due to the high $\mathrm{O}_{2}$ concentration. Carbon deposited on the surface of the methanation catalyst in the presence of $\mathrm{O}_{2}$ or $\mathrm{CO}_{2}$ can be converted into $\mathrm{CO}$, increasing the FID signal for this gas. These interferences are particularly important and must be taken into account when low levels of $\mathrm{CO}$ are analyzed. This is because the retention times (Figures 1a and b) for $\mathrm{CO}$ and first ghost peaks are similar.

A comparison of the areas of the ghost peaks and those of the $\mathrm{CO}$ and $\mathrm{CO}_{2}$ peaks for the diluted (100x) A1 sample (injected under the same condition, $300 \mu \mathrm{L}$ ) demonstrates that the artefacts contributed to quantification of the compounds under study. Thus, according to the interference values for each gas with the samples, the value of first ghost peaks could more significantly compromise $\mathrm{CO}$ quantification than $\mathrm{CO}_{2}$ quantification. It is important to note that the signals observed for $\mathrm{CO}_{2}$ in the real, urban atmosphere and coal mine samples tested were far higher $(>800 \mu \mathrm{V}$.s $)$ than the average interference value $(11 \mu \mathrm{V} \mathrm{s})$, suggesting that this artifact does not compromise quantification of this gas in these samples.

The capillary column was changed in order to assess the behavior of these gases under different chromatographic conditions (carbon molecular sieve phase, method 2). Figure 3 a shows the chromatogram resulting from the injection of standard gas mixture A1. As occurred in method 1, separate peaks were observed for the gases of interest, each with different retention times: $4.182 \mathrm{~min}(\mathrm{CO}), 8.262 \mathrm{~min}\left(\mathrm{CH}_{4}\right)$ and $10.887 \mathrm{~min}\left(\mathrm{CO}_{2}\right)$. The areas of these peaks are proportional to the concentrations of these gases in the standard sample (Table $2 \mathrm{~S}$ ).

Tests were also carried out with other standard gas mixtures (A3; synthetic air) in order to evaluate the behavior of the ghost peaks using method 2. As shown in Figure 3b, the retention times of first ghost peaks (2.923 $\mathrm{min}$ ) and CO (4.182 min, Figure 3a) differ, indicating good separation when analyzed using this method. With respect to the presence of second ghost peaks (similar retention time to $\mathrm{CO}_{2}$, Figures $3 \mathrm{a}$ and $\mathrm{b}$ ), due to the previously mentioned contamination problems, additional analyses were performed injecting A5 $\left(\mathrm{N}_{2}\right)$ with and without fitting a valve on the syringe (Figures $1 \mathrm{Se}$ ). According to Figure 2S, adaptation of the syringe confirmed that the emergence of this peak is related to contamination by outside air, since the ghost peaks were not observed after the injection mechanism was modified. Considering that analyses performed in method 2 did not compromise the quantification of samples containing $\mathrm{CO}$, the limit of detection (LOD) was determined in this method. The tests indicated that the LOD is 13 ppm, below the established value for workplaces (39 ppm, NR-155) such as underground coal mines.

Analyses were carried out for both methods (1 and 2) using car exhaust fume samples to assess the behavior of ambient air samples in the presence of $\mathrm{CO}$ and $\mathrm{CO}_{2}$.

A significant variation was observed in $\mathrm{CO}$ and $\mathrm{CO}_{2}$ levels, as shown in Figure 4. This is due to the combustion process that takes place in the vehicle, since samples were collected at different times during engine acceleration. The results obtained (Figure 4a) demonstrated good correlation and agreement (slope 1.0016, $\mathrm{R}^{2}=0.94$ ) between methods 1 and 2 for $\mathrm{CO}_{2}$ concentrations across a wide range (400-12,500 ppm). More significant differences (slope $0.6997)$ were recorded for CO (20-2,500 ppm, Figure 4b), particularly for samples with high levels $(\geq 1,000 \mathrm{ppm})$ of this gas, despite the good correlation $\left(\mathrm{R}^{2}=0.96\right)$ between the data, suggesting systematic errors.

This result confirms the influence of the artifact caused by the co-elution and simultaneous detection of $\mathrm{CO}$ and the compound(s), likely generated in undesirable reactions between the oxygen in the sample and carbon accumulated in the methanator catalyst, detectable in the FID.

Method 1 is not recommended for $\mathrm{CO}$ analysis in ambient air samples that contain oxygen due to the previously described artifact. When CO quantification is required, under these conditions, this is only possible at concentration above $185 \mathrm{ppm}$.

In these conditions interference of the artifact is three times the value of the noise, similar to the overall accuracy of the method. In the absence of oxygen in the sample, the LOD for $\mathrm{CO}$ in this method is $5 \mathrm{ppm}$. At low $\mathrm{CO}_{2}$ levels, the injection system should be carefully assessed, given that the emergence of second peak is directly associated with this contamination mechanism.

Method 2 is recommended for the simultaneous analysis of all the gases studied here, since no interference was observed in the quantification of the analytes of interest. However, the LOD for CO in this method is $13 \mathrm{ppm}$, which may restrict its use in applications that not require greater sensitivity. It is important to note that the main advantage of method 1 is the short analysis time ( $5 \mathrm{~min}$ ). Additionally, the fact that it is an isothermal method allows direct linking between analyses, thereby improving productivity of the analyses. Method 2 

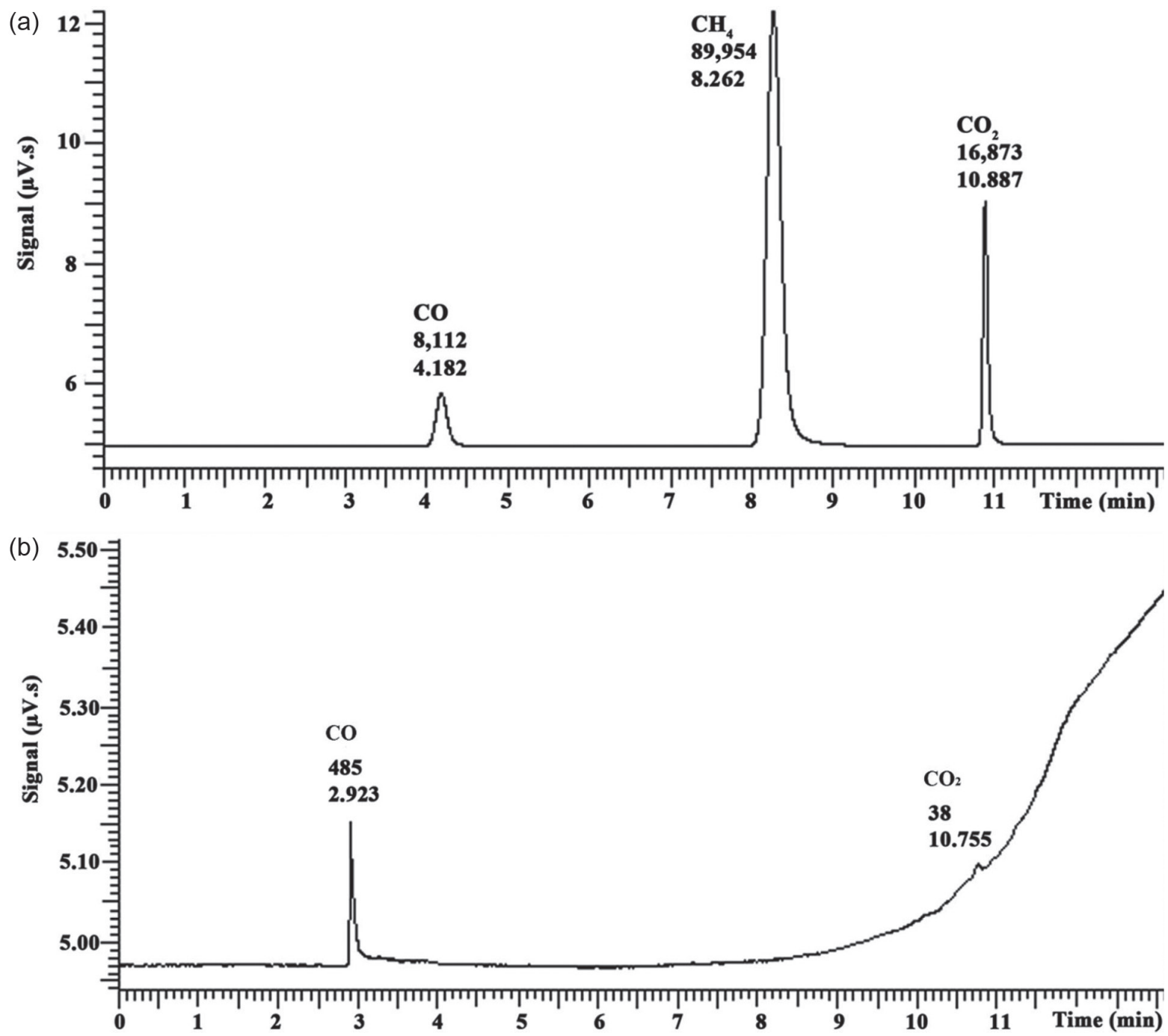

Figure 3. Chromatogram of the standard gas mixtures analyzed by Method 2 for: (a) standard A1 and (b) standard A3
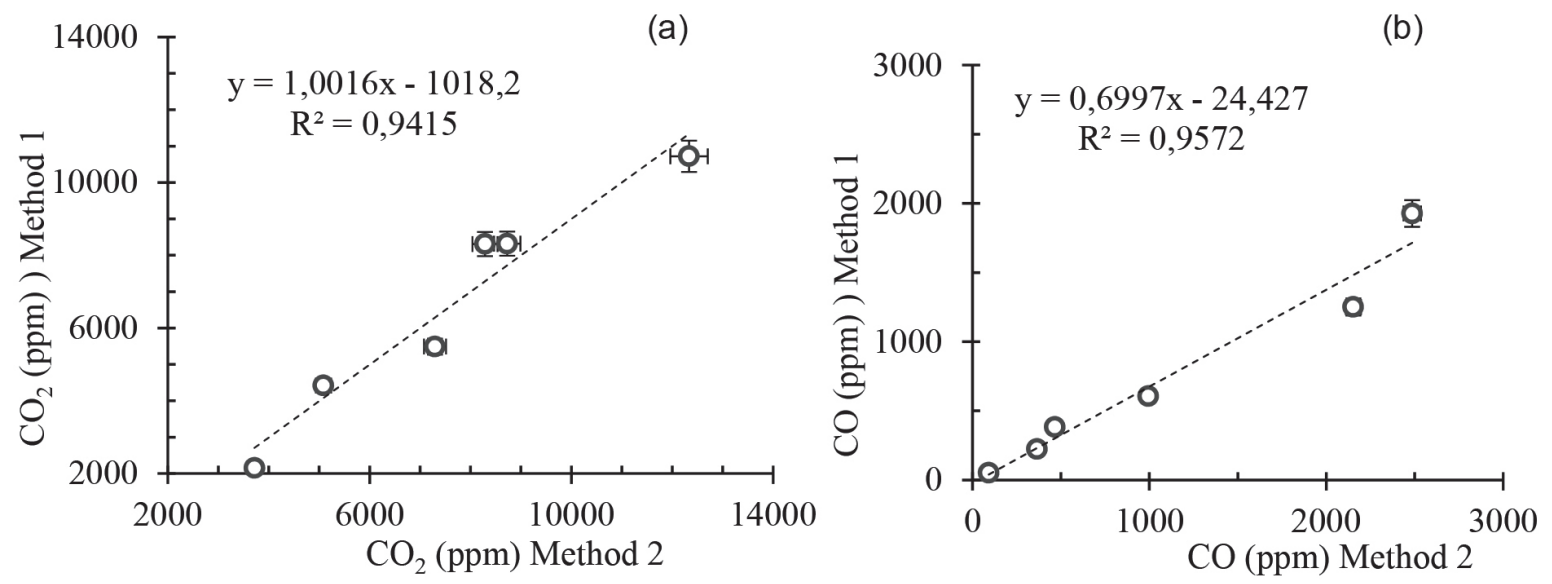

Figure 4. Analysis of car exhaust fume sample using methods 1 and 2 for: (a) $\mathrm{CO}_{2}$ concentrations and (b) CO concentrations

exhibits a longer analysis time $(13 \mathrm{~min})$ and the fact that it uses a temperature gradient means additional equilibrium time is needed between the two injections $(+10 \mathrm{~min})$. The longer analysis time increases the final costs of this method.

\section{Assessment of GHG sampling and storage systems}

Gas sampling in coal mines involves a number of logistical difficulties (low visibility, high temperatures and humidity, and high risk). Given that the chromatographic analyses were conducted in the laboratory far from the collection sites, the samples had to be stored, making it important to ensure their integrity between collection and analysis. Additionally, containers must be easy to use, inexpensive and reusable. In light of these restrictions, 10 different types of containers (Table 1), subdivided into flasks and sampling bags, were tested.

Vacuum level tests on the flasks indicated that $99 \%$ of the level 
was maintained for up to 10 days when compared to flasks tested on the same day. To that end, the initial weight of the flasks filled with water for tests on the same day and after 10 days was compared against the final weight. In regard to flask reusability, vacuum level testing indicated 95 and $90 \%$ maintenance of the vacuum for a third and fifth sampling cycle, respectively, using the same septa. Rochete and Bertrand ${ }^{19}$ also used water to evaluate the vacuum level in preevacuated commercial borosilicate flasks (Extainers ${ }^{\circledR}$, LABCO, UK) with double septa and recorded $98 \%$ recovery in 135 days for flasks with new septa and $96 \%$ for septa used seven times in 63 days.

\section{Synthetic sample}

Initial tests were performed with a synthetic sample prepared by diluting a calibration standard (A1, Table $2 \mathrm{~S}$ ) in nitrogen (A5). Five different sampling flask configurations were tested, one made from polymeric material (VC-R), one from commercial borosilicate (EX$\mathrm{BR}$ ), and the others from reused borosilicate (AF) with three different septum combinations (TS, S and BR), referred to as alternative flasks in this study. Figure 5 shows the storage results for the synthetic sample up to $120 / 240 \mathrm{~h}$, expressed as recovery percentages.

It can be observed that the VC-R flasks with a rubber septum are not reliable for the collection/storage of the three gases studied, showing losses $>90 \%$ in the first $24 \mathrm{~h}$ of storage. Holland et al. ${ }^{22}$ reported the leakage, contamination and adsorption of $\mathrm{CO}_{2}, \mathrm{~N}_{2} \mathrm{O}$ and $\mathrm{CH}_{4}$ samples in the Vacutainers ${ }^{\circledR}$ assessed. The AF-TS flasks displayed stability in the first $48 \mathrm{~h}$ for $\mathrm{CO}(100 \%)$ and $\mathrm{CH}_{4}(92 \%)$,
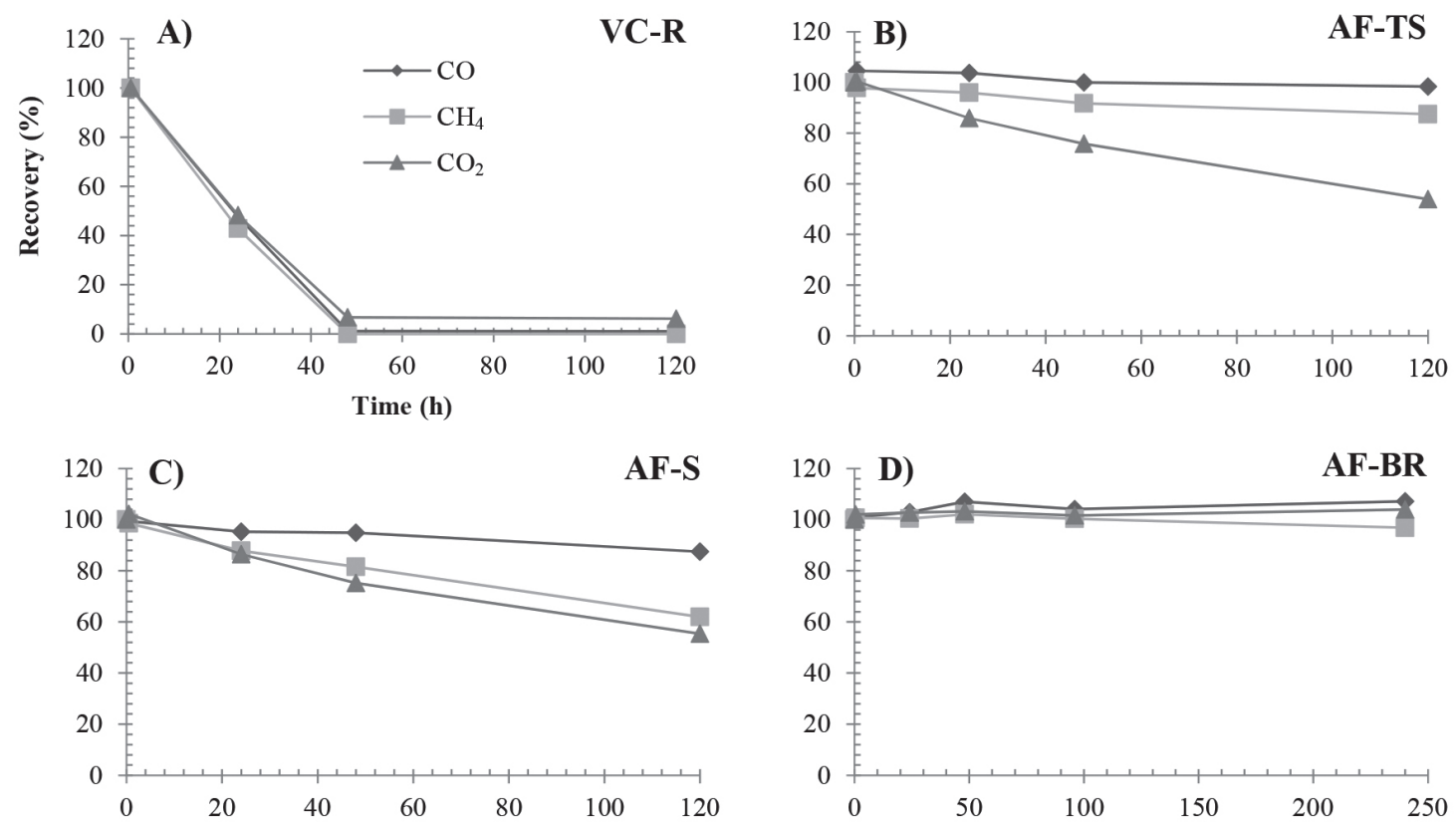

with lower recovery for $\mathrm{CO}_{2}(76 \%)$. At longer time intervals, losses reached $54 \%$ for $\mathrm{CO}_{2}$. The AF-S flasks with a silicone septum and their AF-TS counterparts exhibited similar $\mathrm{CO}_{2}$ recovery; however, it was lower for the remaining gases $\left(\mathrm{CO} 87 \%\right.$ and $\left.\mathrm{CH}_{4} 62 \%\right)$ at $120 \mathrm{~h}$.

AF-BR flasks with butyl rubber septa showed the best results for all the gases studied, maintaining $100 \%$ of the methane samples for up to $96 \mathrm{~h}$. Over longer periods $(240 \mathrm{~h})$, recovery was

$107 \%$ for $\mathrm{CO}$ and $104 \%$ for $\mathrm{CO}_{2}$. These results are similar to those recorded for the commercial flasks (Exetainers ${ }^{\circledR}$, EX-BR), indicating that butyl rubber is less permeable than the other materials. These findings corroborate those of Lange, Allaire and Van Bochove, ${ }^{23}$ who found that borosilicate flasks with butyl rubber septa (chlorobutyl/50) were ideal for storing gas samples $\left(\mathrm{CO}_{2}, \mathrm{~N}_{2} \mathrm{O}\right.$ and $\left.\mathrm{CH}_{4}\right)$, even over extended periods.

It is important to note that values slightly higher than $100 \%$ can occur and are related to the precision of the methods used, which are rarely less than $95 \%$. Since recovery calculations include two concentrations, the values carry errors associated with these two determinations. Glatzel and Well ${ }^{14}$ studied Exetainers ${ }^{\circledR}$ flasks for their suitability in collecting and storing $\mathrm{N}_{2} \mathrm{O}$ (synthetic sample) and found no significant losses, even when storage pressure and temperature were varied over a 10-day period. The authors also observed better storage results when collections were performed with narrower needles. In this case, the number of punctures assessed did not significantly affect gas concentration in the flasks.

Figure 6 shows the recovery percentages of the gases (diluted standard A1), under study when stored in the five sampling bags tested
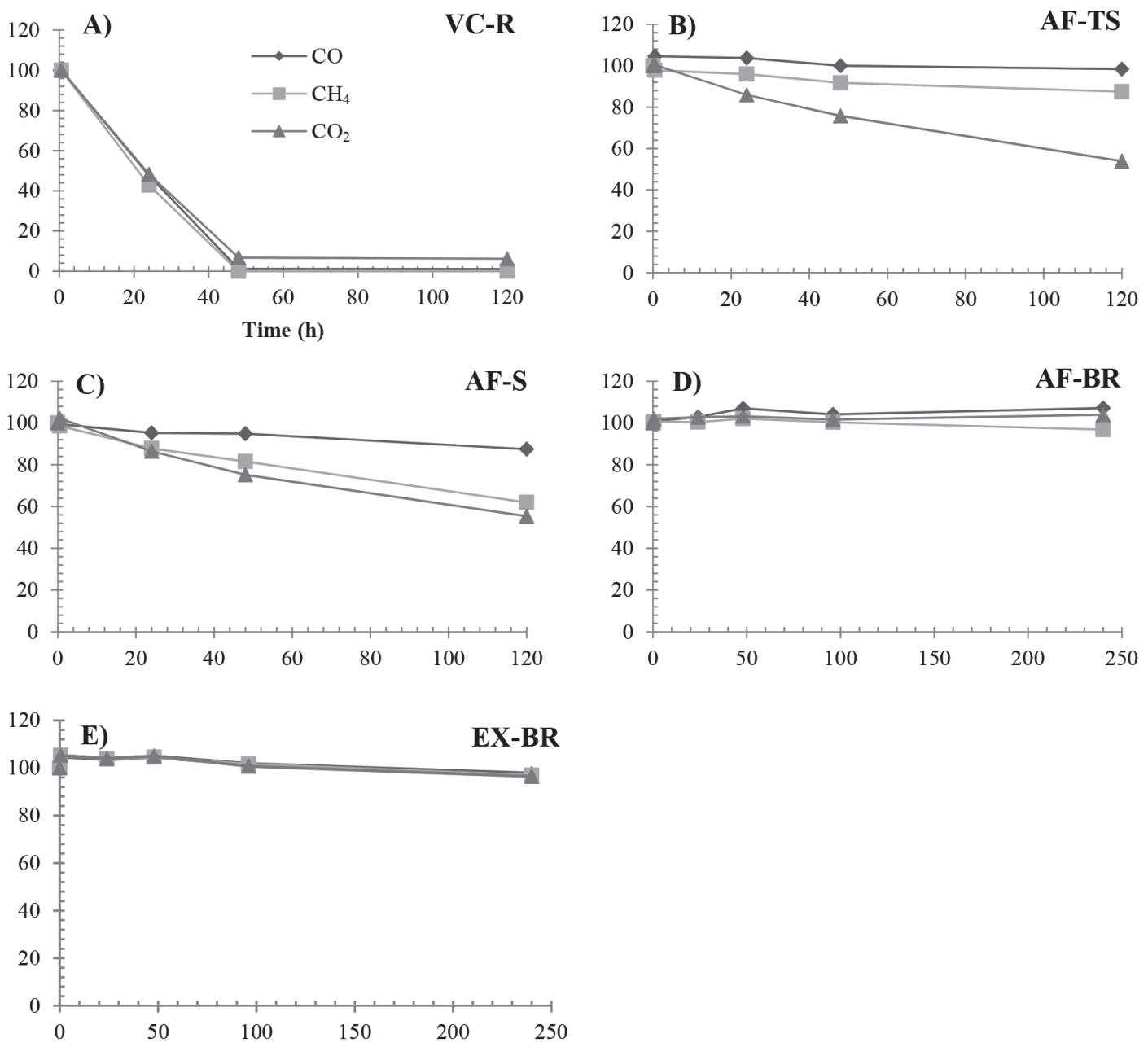

Figure 5. Storage results for $\mathrm{CO}, \mathrm{CO}_{2}$ and $\mathrm{CH}_{4}$ in a synthetic sample, with different flasks 

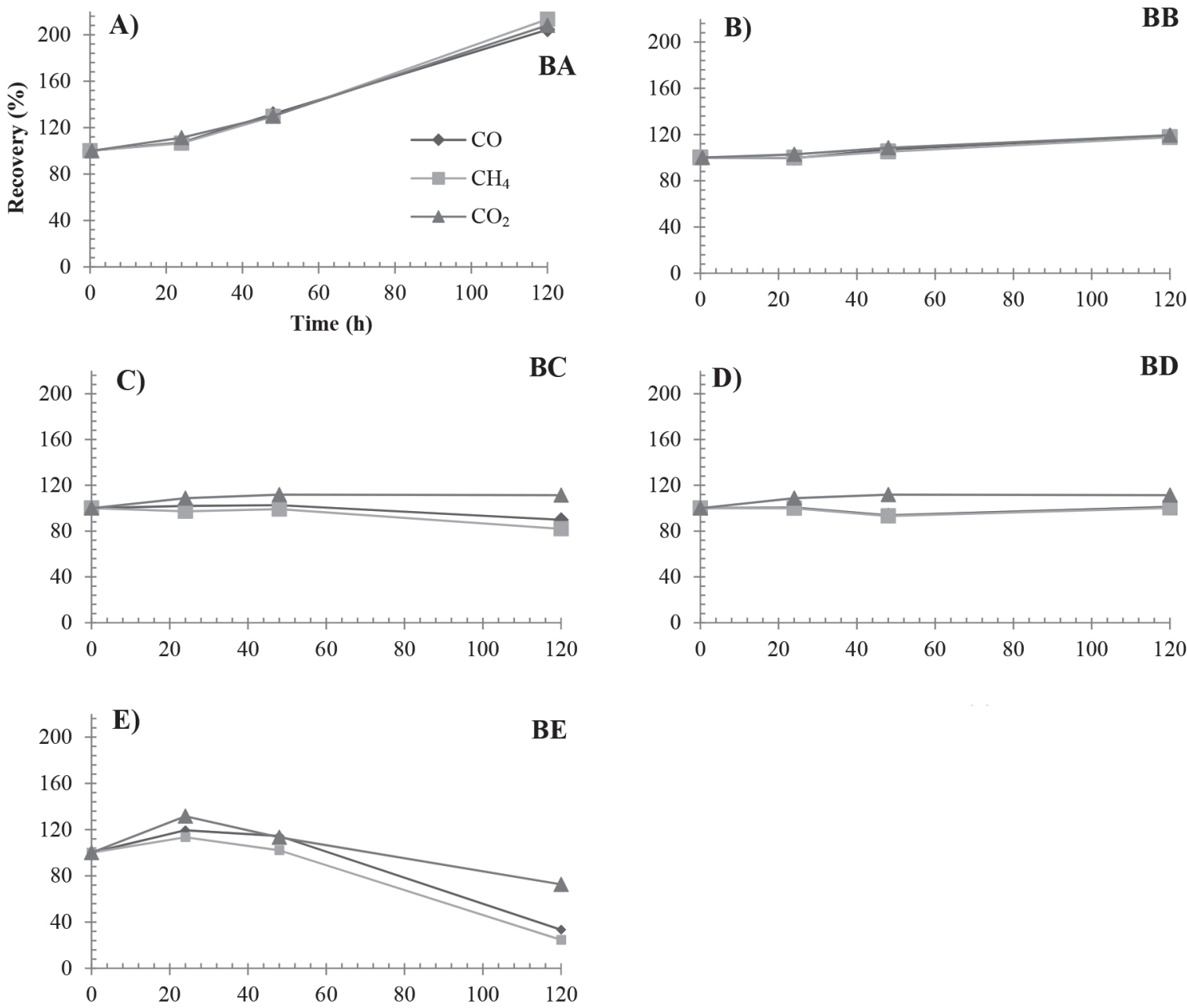

Figure 6. Storage results for $\mathrm{CO}, \mathrm{CO}_{2}$ and $\mathrm{CH}_{4}$ in a synthetic sample, with different sampling bags

(Table 1). The best performance was recorded for the BD bag (Supel ${ }^{\mathrm{TM}}$, inert multilayer foil), since recovery percentages were $100 \%$ after $120 \mathrm{~h}$ for the three gases analyzed. Bags BA and BB exhibited good recovery in the first $48 \mathrm{~h}$, after which the samples were compromised, with a significant increase in recovery percentages (118\% to $213 \%$ ). This unexpected behavior could indicate contamination of the bags or selective permeation of air $\left(\mathrm{O}_{2} / \mathrm{N}_{2}\right)$ through the septum. Bags BC and $\mathrm{BE}$ displayed unsatisfactory performance for $\mathrm{CH}_{4}$, with losses of 18 and $75 \%$ after $120 \mathrm{~h}$, respectively, indicating that the samples were significantly compromised.

\section{Real samples}

A real sample characteristic of polluted urban air was collected inside a tunnel with heavy traffic (Conceição Tunnel, Porto Alegre, Brazil). Samples with $\mathrm{CO}_{2}$ concentrations between 700 and 820 ppm were used in these tests. The results of $\mathrm{CO}_{2}$ recovery as a function of storage time in flasks and bags are shown in Table 2.

AF-BR alternative flasks and EX-BR commercial flasks showed good stability, maintaining $\mathrm{CO}_{2}$ recovery of $95 \%$ and $98 \%$, respectively, for up to $144 \mathrm{~h}$. By contrast, flask AF-TS exhibited a significant decline in recovery $(90 \%)$ after $24 \mathrm{~h}$, declining further to $80 \%$ at 144 h. Spotl ${ }^{24}$ and Glatzel and Well ${ }^{14}$ also reported good results in studies on $\mathrm{CO}_{2}$ and $\mathrm{N}_{2} \mathrm{O}$ storage in Exetainers ${ }^{\circledR}$. The authors analyzed the effect of temperature and pressure during storage and concluded they did not influence gas retention performance within the range studied. The slight variation in gas concentration was attributed to punctures made in the septa during analyte insertion and analysis. Among the sampling bags tested, BD showed the best performance, with recovery of $98 \%$ after $144 \mathrm{~h}$ of storage.

Bags BC and BE exhibited acceptable recovery of 96 and $93 \%$, respectively, after $48 \mathrm{~h}$. However, over longer periods storage in these bags results in more significant analyte reduction (87-88\%). Since they are made from the same material, the difference in concentration variations observed for these two containers is believed to be related to their valves and the gas volume inside them. According to Mochalski et al. ${ }^{25}$ these factors compromise performance and retention ability. Another factor that may explain this difference is the possible interaction between the sample and the component material of the container. ${ }^{26}$ The superior performance of BD is likely related to its low permeability to the analyte, given that it is made from multiple layers of polymer/aluminum. Kim et al. ${ }^{15}$ compares different types of bags, noting that the multilayered aluminum foil container retained gas better than the other materials tested. Over longer storage times, bag BD and flasks AF-BR and EX-BR displayed similar performance.

The soil emission sample was selected for its high $\mathrm{CO}_{2}$ levels compared to those found in ambient air and its high humidity. Similar conditions are expected in the ambient air of coal mines. In these tests to type of flasks were used (AF-S and AF-BR) and in the Figure 3S the obtained results are presented. AF-S flasks showed similar recovery values to those recorded for $\mathrm{CO}_{2}$ in the real sample ( $56 \%$ in $120 \mathrm{~h}$ ), demonstrating possible permeability of the silicone septum to $\mathrm{CO}_{2}$. By contrast, recovery values for $\mathrm{CO}_{2}$ in AF-BR flasks remained high (98\%) even after $96 \mathrm{~h}$, indication good stability and 
Table 2. Concentration variations during storage, for the gases collected in Conceição Tunnel, using different containers

\begin{tabular}{|c|c|c|c|c|}
\hline \multirow{2}{*}{ Container } & \multirow{2}{*}{$\begin{array}{c}\text { Time } \\
\mathrm{h}\end{array}$} & \multicolumn{2}{|c|}{$\mathrm{CO}_{2}$} & \multirow{2}{*}{$\begin{array}{c}\text { Relative } \\
\text { recovery } \mathrm{CO}_{2} \\
\%\end{array}$} \\
\hline & & ppm & $\mathrm{dp} \%$ & \\
\hline \multicolumn{5}{|c|}{ Flasks } \\
\hline \multirow{4}{*}{ EX-BR } & 2 & 740 & 4 & 100 \\
\hline & 24 & 746 & 4 & 101 \\
\hline & 48 & 728 & 5 & 98 \\
\hline & 144 & 726 & 6 & 98 \\
\hline \multirow{4}{*}{ AF-BR } & 2 & 824 & 5 & 100 \\
\hline & 24 & 802 & 5 & 97 \\
\hline & 48 & 771 & 5 & 94 \\
\hline & 144 & 779 & 5 & 95 \\
\hline \multirow{4}{*}{ AF-TS } & 2 & 796 & 4 & 100 \\
\hline & 24 & 720 & 2 & 90 \\
\hline & 48 & 724 & 5 & 91 \\
\hline & 144 & 634 & 4 & 80 \\
\hline \multicolumn{5}{|c|}{ Bags } \\
\hline \multirow{4}{*}{$\mathrm{BC}$} & 2 & 743 & 2 & 100 \\
\hline & 24 & 751 & 2 & 101 \\
\hline & 48 & 713 & 4 & 96 \\
\hline & 144 & 645 & 8 & 87 \\
\hline \multirow{4}{*}{ BD } & 2 & 701 & 0 & 100 \\
\hline & 24 & 723 & 2 & 103 \\
\hline & 48 & 702 & 6 & 100 \\
\hline & 144 & 688 & 2 & 98 \\
\hline \multirow{4}{*}{$\mathrm{BE}$} & 2 & 752 & 4 & 100 \\
\hline & 24 & 764 & 1 & 102 \\
\hline & 48 & 698 & 2 & 93 \\
\hline & 144 & 662 & 2 & 88 \\
\hline
\end{tabular}

low permeability of the butyl rubber septum to the gas analyzed. The results obtained suggest that the septa used on these flasks play a prominent role. Hedley, Sagar and Tate ${ }^{27}$ studied the performance of Exetainers ${ }^{\circledR}$ in the collection and storage of $\mathrm{CH}_{4}, \mathrm{CO}_{2}$ and $\mathrm{N}_{2} \mathrm{O}$ soil emission samples. The authors found that changes in concentration for the three gases were $<5 \%$, even after $90 \mathrm{~h}$ of storage at $20{ }^{\circ} \mathrm{C}$. The alternative flasks tested in the present study showed similar performance to that reported in the literature. The results obtained with the synthetic and real samples demonstrated that flasks AF-S and $\mathrm{VC}-\mathrm{R}$ and bags $\mathrm{BA}$ and $\mathrm{BB}$ are unsuitable for storing the gases of interest. As such, these types of containers were not used in the subsequent tests described below.

Finally, tests were conducted using air samples collected in an underground coal mine. ${ }^{13}$ The recovery results for $\mathrm{CH}_{4}$ and $\mathrm{CO}_{2}$ for the six containers studied are shown in Table 3 . Initial concentrations of the samples used were 1,200 $\mathrm{ppm} \mathrm{CH}_{4}$ and 1,500 $\mathrm{ppm} \mathrm{CO}_{2}$, analyzed $24 \mathrm{~h}$ after collection in the mine and transportation to the laboratory. In these tests, this value was applied as the initial concentration in order to calculate recovery.

The results obtained were similar to those recorded in tests using the other samples studied. The EX-BR flasks showed excellent performance (100-101\%) for both gases for the entire storage time tested (240 h). AF-BR flasks exhibited good recovery (96\%) after $96 \mathrm{~h}$ for both gases, with performance declining (94\%) at the end of the test. By contrast, at $48 \mathrm{~h}$, performance was mediocre for AF-TS, with more significant losses for $\mathrm{CO}_{2}(85 \%)$ than $\mathrm{CH}_{4}(94 \%)$. Lower recovery percentages $\left(\mathrm{CO}_{2} 42 \%\right.$ and $\left.\mathrm{CH}_{4} 39 \%\right)$ were observed at the end of the test. The poor performance of this container for $\mathrm{CO}_{2}$ was previously identified in tests on the urban ambient air sample (Table 2). It should be noted that $\mathrm{CH}_{4}$ losses appear less marked than $\mathrm{CO}_{2}$ losses for most the flasks. This behavior can be explained by the different permeabilities of the septa to the gases analyzed. The flasks with the highest $\mathrm{CO}_{2}$ recovery percentages were those equipped with butyl rubber septa, which is less permeable to this gas when compared to PTFE and silicone..$^{28}$

The BD bags demonstrated high recovery for both gases (98$99 \%$ ) until test completion. Performance for $\mathrm{BC}$ and $\mathrm{BE}$ was similar and unsatisfactory, with recovery of $83 \%$ for $\mathrm{CO}_{2}$ and $63 \%$ for $\mathrm{CH}_{4}$ after $96 \mathrm{~h}$ of storage. More significant reductions were observed at the end of the test, particularly for $\mathrm{CH}_{4}$ (22-28\%). Mochalski et al. ${ }^{29}$ reported that variations in recovery percentages in the bags are associated with the polymers used in their manufacture, among other factors. The aging of these materials can compromise their structure. Cleaning and preparing the containers can also affect their performance. The performance of the sampling bags depends on their component material and useful life. The manufacturers guarantee sample retention and integrity when stored in this type of bag for up to $48 \mathrm{~h} .{ }^{18} \mathrm{Ahn}$, Deep and $\mathrm{Kim}^{16}$ recommend using polyester aluminum to store samples of biogenic volatile organic compounds present in ambient air.

It is important to underscore that the bags are sold for single use; however, they are reused in most studies, with several articles analyzing cleaning methods and the number of collection/cleaning cycles they can be submitted to. ${ }^{29,30}$ These usage restrictions, and particularly the maximum storage time, compromise the use of sampling bags in studies conducted in more remote areas. This is the case for the coal mines in the present study, which are $400 \mathrm{~km}$ from the laboratory where analyses were conducted. Other important aspects to be considered when selecting containers are their ease of use and cost. Flasks are simpler and easier to use than sampling bags owing to their smaller volume and sampling procedure. Whereas flasks require only a plastic syringe for sampling, a relatively heavy $(2.3 \mathrm{~kg})$ and costly (US\$ $1,070.00)$ vacuum sampling pump is needed for the bags (Table 1). Based on the overall assessment of the results obtained, flasks AF-BR and EX-BR displayed superior performance for the two gases studied when compared to the remaining flasks and the sampling bags. Flask AF-BR, produced in the laboratory using recycle materials, was less expensive (US\$ 1.22) and more widely available than EX-BR (US\$1.57), which has to be imported and is made by a single manufacturer (Table 1). Among the sampling bags studied, BD (multilayered PE/Al) exhibited good performance, but its use is limited due to cost and logistics.

\section{CONCLUSIONS}

An artifact in chromatographic analysis, due to $\mathrm{CO}$ co-elution with a ghost peak (P1) and its interference in the FID signal, demanded a more detailed assessment of the standard method used (method 1, polystyrene-divinylbenzene phase column) and the proposal of an alternative analysis method (method 2, carbon molecular sieve phase column). It was concluded that method 1 is not suitable for $\mathrm{CO}$ analysis in samples with low levels of this gas due to interference by oxygen. Method 2 is recommended for the simultaneous analysis of the gases of interest, since there is no interference in the quantification of these analytes. However, the 
Table 3. Concentration variations during storage for the gases collected in the coal mine using different containers

\begin{tabular}{|c|c|c|c|c|c|c|c|}
\hline \multirow{2}{*}{ Container } & \multirow{2}{*}{$\begin{array}{l}\text { Time } \\
\text { (h) }\end{array}$} & \multicolumn{2}{|c|}{$\mathrm{CO}_{2}$} & \multicolumn{2}{|c|}{$\mathrm{CH}_{4}$} & \multicolumn{2}{|c|}{ Relative recovery (\%) } \\
\hline & & ppm & $\mathrm{dp} \%$ & ppm & $\mathrm{dp} \%$ & $\mathrm{CO}_{2}$ & $\mathrm{CH}_{4}$ \\
\hline \multicolumn{8}{|c|}{ Flasks } \\
\hline \multirow{4}{*}{ EX-BR } & 24 & 1,511 & 2 & 1,215 & 6 & 100 & 100 \\
\hline & 48 & 1,564 & 3 & 1,253 & 4 & 103 & 103 \\
\hline & 96 & 1,526 & 4 & 1,235 & 3 & 101 & 102 \\
\hline & 240 & 1,517 & 5 & 1,227 & 3 & 100 & 101 \\
\hline \multirow{4}{*}{ AF-BR } & 24 & 1,691 & 3 & 1,137 & 1 & 100 & 100 \\
\hline & 48 & 1,697 & 1 & 1,129 & 2 & 100 & 99 \\
\hline & 96 & 1,624 & 3 & 1,093 & 1 & 96 & 96 \\
\hline & 240 & 1,589 & 3 & 1,064 & 4 & 94 & 94 \\
\hline \multirow{4}{*}{ AF-TS } & 24 & 1,361 & 13 & 876 & 18 & 100 & 100 \\
\hline & 48 & 1,152 & 11 & 822 & 16 & 85 & 94 \\
\hline & 96 & 836 & 9 & 708 & 13 & 61 & 81 \\
\hline & 240 & 576 & 10 & 340 & 12 & 42 & 39 \\
\hline \multicolumn{8}{|c|}{ Bags } \\
\hline \multirow{4}{*}{$\mathrm{BC}$} & 24 & 1,420 & 5 & 1,088 & 19 & 100 & 100 \\
\hline & 48 & 1,391 & 5 & 935 & 10 & 98 & 86 \\
\hline & 96 & 1,178 & 9 & 680 & 16 & 83 & 63 \\
\hline & 240 & 831 & 13 & 244 & 43 & 59 & 22 \\
\hline \multirow{4}{*}{ BD } & 24 & 1,479 & 1 & 1,197 & 6 & 100 & 100 \\
\hline & 48 & 1,490 & 0 & 1,189 & 7 & 101 & 99 \\
\hline & 96 & 1,445 & 1 & 1,170 & 7 & 98 & 98 \\
\hline & 240 & 1,450 & 1 & 1,184 & 5 & 98 & 99 \\
\hline \multirow{4}{*}{$\mathrm{BE}$} & 24 & 1,400 & - & 1,000 & - & 100 & 100 \\
\hline & 48 & 1,334 & - & 880 & - & 95 & 88 \\
\hline & 96 & 1,157 & - & 631 & - & 83 & 63 \\
\hline & 240 & 883 & - & 284 & - & 63 & 28 \\
\hline
\end{tabular}

high LOD for CO (13 ppm) and longer analysis time (20 min) when compared to method 1 (5 $\mathrm{min}$ ) could restrict its use in applications do not requiring greater sensitivity and rapidity of the analysis. The results obtained in the present study clearly demonstrate the need for a detailed assessment of the analytical methods, especially for samples containing oxygen and low to medium levels of $\mathrm{CO}$, as occurs in the ambient air in underground coal mines.

An alternative collection system for the sampling and storage of greenhouse gases was evaluated against different commercial containers. The AF-BR system, consisting of a reusable borosilicate flask with two septa (PTFE/Silicone + Butyl rubber/PTFE), ensured the stability (recovery $>95 \%$ ) of the gases of interest for up to $96 \mathrm{~h}$. This performance was similar to the commercial flask, which is $25 \%$ more expensive and less easily available. Flask AF-BR offers several advantages over traditional containers in terms of cost (90\% less), ease of use and reusability (up to 5 evacuation/sampling/analysis cycles without changing septa). For samples with higher volume, it is recommended to use the $\mathrm{BD}$ (PE / Al Multi-Layer Foil) sample bag, since it presented better performance than the other bags tested.

\section{SUPPLEMENTARY MATERIAL}

Extra details and results on chromatographic methods used can be freely accessed online at http://quimicanova.sbq.org.br, in PDF format.

\section{ACKNOWLEDGMENTS}

The authors are grateful to the CNPq (490218/2012-1, 312323/2015-8), FAPERGS, CAPES for awarding grants and to Prof. C. Bayer (UFRGS) for donating the commercial sampling flasks.

\section{REFERENCES}

1. Bessou, C.; Ferchaud, F.; Gabrielle, B.; Mary, B.; Agron. Sustain. Dev. 2011, 31, 1 .

2. $\mathrm{CO}_{2}$ Emissions from Fuel Combustion, International Energy Agency, Paris, France, 2016, https://www.iea.org/, accessed October 2018.

3. Coal Meeting the Climate Challenge, Technology to Reduce Greenhouse Gas Emissions, World Coal Institute, Richmond, United Kingdom, https://www.worldcoal.org, Accessed: July 2018.

4. Rede Estadual de monitoramento automático da qualidade do ar. Relatório 2015. Fepam: Porto Alegre, http://www.fepam.rs.gov.br, accessed October 2018.

5. Norma regulamentadora: NR15, Atividades e Operações Insalubres, Portaria MTb n 3.214, Brasília, 2014.

6. Mine Safety and Health Administration; Federal Register v. 66, n. 13, 182 p, 2001, USA.

7. Kawaragi, K.; Sekine, Y.; Kadono, T.; Sugita, S.; Ohno, S.; Ishibashi, K.; Kurosawa, K.; Matsui, T.; Ikeda, S.; Earth Planet. Sci. Lett. 2009, 
$282,56$.

8. Franco, M. G; Corrêa, S. M.; Marques, M.; Perez, D. V.; Water Air Soil Pollut. 2014, 225, 1879.

9. Klee, M. S. In Gas Chromatography; Poole, C., ed.; Elsevier: New York, 2012, chap. 12.

10. Santamaría, C.; Elustondo, D.; Lasheras, E.; Santamaría, J. M.; In Chromatographic Analysis of the Environment; Nolletet, L. M. L., Lambropoulou, D. A., eds.; Taylor \& Francis Group: Boca Raton, 2017, chap. 13

11. Kaminski, M.; Kartanowicz , R.; Jastrzebski, D.; Kamiński, M. M.; J. Chromatogr. A 2003, 989, 277.

12. He, X.; Liu, M.; Wang, E.; In Mining science and technology; Yuguang, G., Golosinki, T. S., eds., A. A. Balkema: Rotterdam, 1996.

13. Marć, M.; Tobiszewski, M.; Zabiegała, B.; Guardia, M.; Namieśnik, J.; Anal. Chim. Acta. 2015, 853, 116.

14. Glatzel, S.; Well, R.; Environ. Monit. Assess. 2008, 136, 307.

15. Kim, Y-H., Kim, K. H.; Jo, S. H.; Jeon, E. C.; Sohn, J. R.; Parker, D. B.; Anal. Chim. Acta, 2012, 712, 162.

16. Ahn, J-H.; Deep, A.; Kim, K-H.; Atmos. Environ. 2016, 141, 430.

17. Peach, M. J.; Carr, W. G. In Occupational respiratory diseases; Merchant, J. A., Bochlecke, B. A., Taylor, G., eds.; UNIOSH Publication: Morgantown, 1986, No. 86-102, Section I.

18. The next Generation of SKC Sample Bags. SKC Limited. www.skcltd. com, accessed October 2018.

19. Rochette, P.; Bertrand, N.; Can. J. Soil Sci. 2003, 83, 631.
20. Abruzzi, R. C.; PhD Thesis, Pontifícia Universidade Católica do Rio Grande do Sul, Brasil, 2017.

21. Van Rensburg, M. J. Botha, A.; Rohwer, E.; J. Chromatogr. A 2007, 1167, 102.

22. Holland, E. A. Robertson, G. P.; Greenberg, J.; Groffman, P. M.; Boone, R. D.; Gosz, J. R. In Standard Soil Methods for Long-Term Ecological Research; Robertson, G. P., Coleman, D. C., Bledsoe, C. S., Sollin, P., eds.; Oxford University Press: New York, 1999, chap 10.

23. Lange, S. F.; Allaire, S. E.; Van Bochove, E.; J. Environ. Monit. 2008, 10,775 .

24. Spotl, C.; Rapid Commun. Mass Spectrom. 2004, 18, 1239.

25. Mochalski, P.; Wzorek, B.; Sliwka, I.; Amann, A.; J. Chromatogr. B 2009, 877, 189.

26. Jo, S-H.; Kim, K. H.; Shon, Z. H.; Parker, D.; Anal. Chim. Acta 2012, $738,51$.

27. Hedley, C. B.; Saggar, S.; Tate, K. R.; Commun. Soil Sci. Plant Anal. 2006, 37, 1501 .

28. Shin-Etsu, Characteristics properties of Silicone Rubber Compounds, Japan, 2005. http://www.shinetsusilicone-global.com, accessed October 2018.

29. Mochalski, P.; King, J.; Unterkofler, K.; Amann, A.; Analyst 2013, 138, 1405 .

30. Fan, Z.; Zhang, J.; Fan, C-W.; Pennise, D. M.; J. Air Waste Manage. Assoc. 2001, 51, 60 . 